\title{
FUNDAMENTOS EPISTEMOLÓGICOS DE REPRESENTAÇÕES SOCIAIS EM DISSERTAÇÕES NA ÁREA DE EDUCAÇÃO EM CIÊNCIAS
}

\author{
EPISTEMOLOGICAL FOUNDATIONSOF SOCIAL REPRESENTATIONS \\ IN DISSERTATIONS IN THE AREA OF SCIENCE EDUCATION
}

\author{
Ariwilson Gomes dos Santos ${ }^{1}$ \\ José Alexandre da Silva Valente ${ }^{2}$
}

\begin{abstract}
RESUMO
Neste artigo, objetivamos discutir os fundamentos epistemológicos subjacentes a pesquisas sobre Representações Sociais na área de Educação em Ciências. Para isso, fizemos uma busca por trabalhos (dissertações e teses) em sites de programas brasileiros de Pós-Graduação na área de Educação em Ciências e Matemática, defendidas entre os anos de 2006 e 2010. Examinamos 04 dissertações e constatamos que as pesquisas estão baseadas nas ramificações da Teoria das Representações Sociais e ancoradas nos níveis de estudos fenomenológicos, por discutir objetos representados por grupos sociais, e metateóricos, por fazer dialogar elementos de outras teorias.
\end{abstract}

Palavras-chave: Epistemologia da Pesquisa; Representações Sociais; Educação em Ciências.

\begin{abstract}
In this article we aim to discuss the epistemological foundations underlying the research on social representations in the area of Science Education. For this we searched for academic work (theses and dissertations) in sites of Brazilian Graduate Programs in Science and Mathematics Education, defended between the years 2006 and 2010. We examined 04 dissertations and found that theresearch is based on the ramifications of social representations theory and anchored in the levels of phenomenological studies, by discussing objects represented by social groups, and meta-theoretical, by making dialogue elements from other theories.
\end{abstract}

Keywords: Research Epistemology; Social Representations; Science Education.

\footnotetext{
${ }^{1}$ Doutorando do PPGECM do Instituto de Educação Matemática e Científica - IEMCI/UFPA, Bolsista da Coordenação de Aperfeiçoamento de Pessoal de Nível Superior - CAPES. E-mail: aricristao@ gmail.com.

2 Doutorando do PPGECM do Instituto de Educação Matemática e Científica - IEMCI/UFPA, Professor da Escola de Aplicação da UFPA. E-mail: alexvalt0@yahoo.com.br.

AMAZÔNIA - Revista de Educação em Ciências e Matemáticas V.8 - no 16 - jan. 2012 / jun. 2012, p. 174 -185.
} 


\section{INTRODUÇÃO}

A epistemologia das Representações Sociais (RS) sugere que busquemos incursões em vários campos do conhecimento, os quais, muitas vezes, nem sempre se aproximam das nossas habilidades e competências adquiridas na formação inicial. Logo, este artigo surge oportunamente, haja vista que, na área da Educação em Ciências e Matemática (ECM), os conceitos científicos emergem como foco dos processos de ensino e de aprendizagem.

Nos últimos anos, pesquisas com base na Teoria das Representações Sociais (TRS) parecem caminhar lentamente para se constituir como tendência de pesquisa na ECM, pois, em muitos Programas de Pós-Graduação em ECM do Brasil, o número de pesquisadores que se ancoram nessa teoria para fundamentar suas pesquisas é ainda pouco representativo.

Com base nessa situação, organizamos este artigo com o intuito de identificar e discutir os fundamentos epistemológicos subjacentes a pesquisas sobre Representações Sociais na área de Educação em Ciências.

Imbuídos desta missão, criamos uma questão que pudesse nos guiar nesse caminho, a saber: quais os fundamentos epistemológicos das representações sociais presentes em dissertações defendidas na área de educação em ciências e matemática no Brasil nos últimos cinco anos?

Para responder a tal questão percorremos um caminho, o qual contemplasse as dimensões epistemológicas da pesquisa sobre representações em Educação em Ciências, a saber:

1. Fizemos uma busca nos sites dos Programas de Pós-Graduação em ECM do Brasil (entre 15/04/2011 e 15/07/2011) para reunirmos as teses e dissertações defendidas e disponíveis, as quais tivessem como corpus a Teoria das Representações Sociais;

2. A pesquisa teve como palavra-chave somente Representações Sociais. Com isso, 12 (doze) trabalhos foram encontrados, e, então, organizamos um banco de dados com dissertações, pois não conseguimos encontrar teses;

3. Escolhemos 04 dissertações de Programas e objetos de estudos diferentes em que constavam: as representações sociais do conceito de tempo por graduandos de uma Universidade Pernambucana; representações sociais do termo orgânico por estudantes de uma Universidade Paulista; representações sociais da Física Newtoniana por docentes de uma Universidade Paranaense; e Representações Sociais de Ambiente por professores e estudantes em Diferentes Contextos Educacionais;

4. O critério para escolha de 04 dissertações foi o fato de terem sido defendidas entre 2006 e 2010. Verificadas em seu conteúdo, organizadas e lidas, foram identificadas - com o intuito de manter o anonimato - pelo ano de defesa e pelos símbolos D1, D2, D3 e D4, a fim de discutirmos os fundamentos epistemológicos da TRS;

5. Baseados na leitura, destacamos os aspectos epistemológicos dos textos escolhidos, para observamos as tendências, grupos sociais investigados e elementos que indicam construção e análise de informações concernentes à TRS; 
6. Logo, feita a organização das tendências, construímos seções deste meta-texto que indicam análises ancoradas em conceitos, discussões e teorias relacionadas às abordagens epistemológicas da Teoria das Representações Sociais amparadas em excertos dos trabalhos escolhidos para análise.

Amparados nesta metodologia, organizamos este artigo em seções que discutem as ramificações e os níveis de estudo sobre a TRS, além da origem do termo e da teoria propriamente dita. Tratamos ainda da Complexificação, Núcleo Central das RS e terminamos com algumas considerações que podem indicar caminhos para novos estudos desta natureza.

\title{
RAMIFICAÇÕES E NÍVEIS DE ESTUDO DAS REPRESENTAÇÕES SOCIAIS
}

A Teoria das Representações Sociais, a qual foi concebida em perspectiva de processo, com etapas e ramificações, desdobra-se em elementos de complexificação, inserções sociais dos grupos produtores de representação e, ainda, aspectos estatístico estruturais.

Ao tratarmos de Representações Sociais, a primeira ideia a ser destacada é que ela se refere, inicialmente, ao diálogo entre, pelo menos, dois tipos de conhecimento: a ciência e o senso comum. Exemplo deste diálogo está explícito no seguinte comentário:

\begin{abstract}
Dualidade do tempo, "físico" e o "social", foi cada vez mais se aprofundando com o avanço das ciências físicas. Esse dualismo arraigou-se a ponto de as pessoas partirem dele, como se fosse uma verdade em si. Com relação ao tempo de "natureza física", o mesmo se apresenta como uma das variáveis imutáveis que os físicos medem e que desempenham seu papel nas equações matemáticas, consideradas como representações simbólicas das "leis" da natureza. Enquanto isso, o "tempo social" tem o caráter de uma instituição social, de uma instância reguladora dos acontecimentos sociais, de uma modalidade da experiência humana e os relógios são parte integrante dessa instância reguladora, pois o mesmo é, também, parte integrante de uma ordem social (D2, 2006, p. 47).
\end{abstract}

A ciência trataria de teoria e de conceitos (tais como: ancoragem, objetivação, Núcleo Central), como conhecimento sistemático, organizado, objetivo, trabalhados como Universos Reificados (das ciências) dos saberes construídos e compartilhados cotidianamente.

Conceitos oriundos da grande teoria como Universos Reificados e Universos Consensuais se referem ao trânsito de saberes da ciência para o senso comum (Moscovici, 2003) e estão implícitos no seguinte excerto referência:

[Na] passagem dos conhecimentos científicos aos escolares atua as ressignificações, ou melhor, as Representações Sociais, resultantes das interações sociais que ocorrem no cotidiano das famílias, entre amigos, na escola, no trabalho, no lazer... (D1, 2007, p. 8).

Este fragmento representa uma naturalização da hierarquia entre as formas de construção de conhecimentos, imputando à Ciência o status de saber superior aos outros tipos de saberes.

Quando se trata de senso comum, expresso por meio de opiniões, ideias, concepções, percepções, etc., fala-se de RS como conhecimento construído na prática social diária, sem a preocupação com a organização e sistematização na elaboração de conceitos, isto é, engloba os universos consensuais de pensamentos, em que conhecimentos são adquiridos naturalmente, nas experiências do dia-a-dia dos grupos sociais. 
Fica então evidenciada a multidimensionalidade das interações sociais e as especificidades dos indivíduos em coletividade, pois

estudar as representações sociais é também compreender como a sociedade pensa, age e se comunica, pois os seres humanos, em suas relações cotidianas, criam e transmitem as representações dos objetos (ideias, conceitos, fenômenos) com os quais interagem (D1, 2007, p. 14).

Especificamente falando da teoria das RS, na dissertação D4, apoiado em De Rosa (1994) apud Oliveira e Werba (2008, p. 105-106), afirma-se que essa representação pode ser dividida em três níveis de estudos (discussões e análises):

1) Nível Fenomenológico: em que as RS constituem um objeto de investigação. [...] são elementos da realidade social, são modos de conhecimento, saberes do senso comum que surgem e se legitimam na conversação interpessoal cotidiana e têm como objetivo compreender e controlar a realidade social;

Nesse contexto, conceitos de força e massa são característicos do meio científico e também do nosso dia-a-dia, no entanto, quando solicitados, nós selecionamos, em nossa mente, os elementos do conceito que nos interessam. Quando falamos da Força Peso, por exemplo, os alunos geralmente associam esse conceito a uma característica intrínseca do objeto - "eu vou me pesar!" - com objetivo de trazer o conceito a sua realidade... (D1, 2007, p. 16).

2) Nível Teórico: seria um conjunto de definições conceituais e metodológicas, construtos, generalizações e proposições referentes às RS;

3) Nível Metateórico: seria o nível das discussões sobre a teoria. Nesse, colocam-se os debates e as refutações críticas com respeito aos postulados e pressupostos da teoria, juntamente a uma comparação com modelos teóricos de outra teoria.

Esses níveis de estudos estão intimamente relacionados às ramificações da grande teoria das representações sociais, as quais são constituídas de elementos socialmente sensíveis aos grupos de indivíduos sejam eles organizados considerando quaisquer critérios.

Há várias possibilidades de representação de objetos ou situações da realidade, o que fica evidente no seguinte excerto:

Quando adotamos a Teoria das Representações Sociais, estávamos conscientes de que não se constitui em novidade o fato de que as pessoas possam exibir diferentes formas de ver e representar a realidade à sua volta (D2, 2006, p. 31).

Corroborando com esse raciocínio, chama atenção o entendimento da ciência e da Física como uma, dentre incontáveis possibilidades, de representação da realidade, disposto no seguinte trecho:

\begin{abstract}
Consideramos a ciência de um modo geral e a física de modo particular como um modo de representação do mundo, sempre sujeito à reformulação. Por exemplo, a lei da gravitação universal de Newton é uma forma de representar, por meio de um modelo matemático, a interação entre corpos celestes, sendo, portanto, uma representação simbólica de um tema científico proveniente de um conjunto de relações entre meio e indivíduo (D1, 2007, p. 24-25).
\end{abstract}

A relação e aproximação entre sujeito e objeto são necessárias para que ocorra o fenômeno de representação, para isso, o objeto precisa fazer parte da prática social cotidiana (SÁ, 1998) dos grupos investigados. Representação de temas, conceitos e fenômenos por grupos sociais constitui um resumo das concepções teóricas de Ivana Marková (2006), o qual se caracteriza pela ideia de que para se concretizar pesquisas sobre RS é necessário que se verifique três elementos como pertencentes da mesma dimensão: Alter, Ego e Objeto. 
Estes elementos formam uma tríade dialógica que sustenta a existência das Representações Sociais (D4, 2010, p. 46). O alter constitui as heranças sócio-culturais que os indivíduos recebem; o ego corresponde à manifestação da personalidade individual; e o objeto é o instrumento - ideia, opinião, concepção sobre alguma coisa ou alguém - base da construção da representação social (MARKOVÁ, 2006, p. 213).

Se o indivíduo/grupo é um/a sujeito/coletividade culturalmente constituído/a, recebendo heranças dos saberes de gerações passadas, então um fenômeno, conceito ou situação podem ser dignos de investigação se fizerem parte do cotidiano desse indivíduo/grupo social. Para isso, é necessário, como afirma Sá (1998, p. 26), transformar conceitualmente um fenômeno do universo consensual em um problema do universo reificado.

\section{REPRESENTAÇÕES SOCIAIS: ORIGENS DO TERMO E DA TEORIA}

O precursor da Teoria das Representações Sociais, Serge Moscovici, ao fazer uma pesquisa sobre a representação social da psicanálise, concluiu que a compreensão da ciência pelo senso comum não é, como se crê, uma vulgarização das partes de uma dada ciência, mas sim, a formação de um outro tipo de conhecimento, adaptado a outras necessidades e obedecendo a outros critérios, num determinado contexto.

A representação social se refere ao diálogo entre, pelo menos, dois tipos de conhecimento: a ciência e o senso comum (SANTOS, 2010). Ou melhor, refere-se ao trânsito de conhecimentos, saberes e informações - relevantes aos grupos sociais - da dimensão sistematizada do conhecimento para a dimensão sensitiva e informal do conhecimento do cotidiano (SPINK, 1993).

O conceito de representação nasceu na sociologia e na antropologia. Foi obra de Émily Durkheim e de Lévi-Bruhl. Mas a teoria das Representações Sociais, forma sociológica da psicologia social, tem origem na Europa com a publicação feita por Serge Moscovici (1961) de seu estudo La Psychanalyse: Son image et son public.

Moscovici afirma que a noção de representação coletiva de Durkheim descreve ou identifica uma categoria que deve ser explicada a um nível inferior. É aqui que surge a noção de representação social de Moscovici. Ele julgou mais adequado, num contexto moderno, estudar as representações sociais numa perspectiva psicossocial.

Para diferenciar os conceitos de representação social (RS) e representações coletivas, o estudioso no assunto Pedrinho Guareschi aponta uma analogia interessante, que facilita a compreensão do conceito de RS, argumentando que existem dois tipos de representação:

\footnotetext{
[...] algumas delas se transmitem vagarosamente por gerações; são o que chamamos de tradições e são comparadas à endemia. Outras representações, típicas das culturas modernas, se espalham rapidamente por toda a população, mas possuem um curto período de vida; são o que chamamos de moda e são comparadas à epidemia". O primeiro tipo corresponderia ao conceito de representações coletivas de Durkheim; o segundo, ao conceito de representações sociais de Moscovici (GUARESCHI, 2000, p.196).
}

Para Durkheim, em suas etapas do pensamento sociológico, a principal meta era de encontrar e explicar aquilo que gerava unidade à vida social, o elo entre as diversas formas como as sensações individuais (entendendo o indivíduo como produto da realidade social) são representadas, sua causa "objetiva", "universal" e "eterna". E a resposta vem, num primeiro momento, por meio do conceito de consciência coletiva. A associação dos homens 
(indivíduos), sua síntese, produz um todo (realidade social) que se sobrepõe às partes que o formam.

O termo social, diferentemente de coletivo, sugere o aspecto dinâmico e a bilateralidade no processo de constituição das representações sociais, apontando dois caminhos: Um com aspectos mais científicos e outro mais relacionado ao senso-comum a representação como conhecimento construído e disseminado socialmente; segundo, suas dimensões psicológica, afetiva e analógica, constituinte do comportamento individual (SANTOS, 2010).

\section{A COMPLEXIFICAÇÃO DAS REPRESENTAÇÕES SOCIAIS}

As representações são medidas sociais da realidade, produto e processo de uma atividade de elaboração psicológica e social dessa realidade nos processos de interação e mudança social (JODELET, 1986, p.37). Falar em representação social, portanto, é mais que falar em opinião (individual ou pública), atitude e conduta.

Para entender a complexidade da estrutura das RS, Sá (1993, p. 34) apresenta ideias descritas metaforicamente por Moscovici, em que a representação tem duas faces tão pouco dissociáveis quanto a frente e o verso de uma folha de papel: a face figurativa e a face simbólica. (...) Representação [é igual à] figura/significação, entendendo por isso que ela faz compreender em toda figura um sentido e em todo sentido uma figura.

Para Morin (1990), a representação é simultaneamente uma construção e uma tradução da realidade. Assim, segundo Morin, "só percebemos o real através da representação" (D3, 2007, p. 22). Ou seja, há uma interdependência entre a matéria e a interpretação.

Dessa configuração metafórica é que surgem os primeiros processos formadores das RS, as duplicações: sentido/figura, naturalização, materialização, que recebeu o nome de objetivação; e figura/sentido, interpretação, fornecimento de contexto inteligível, que recebeu o nome de ancoragem.

Objetivar, a rigor, é tornar concreto o objeto pensado, isto é, materializar conceitos e idéias. Ou como nos sugere Oliveira \& Werba (2008, p. 109 - 110):

Objetivação é o processo pelo qual procuramos tornar concreto, visível, uma realidade. Procuramos aliar um conceito com uma imagem, descobrir a qualidade icônica, material de uma idéia, ou algo duvidoso. A imagem deixa de ser signo e passa a ser uma cópia da realidade. Um dos exemplos (...) refere-se à religião. Ao se chamar de "pai" a Deus, está-se objetivando uma imagem jamais visualizada (Deus), em uma imagem conhecida (pai), facilitando assim a idéia do que seja "Deus".

Segundo Jodelet $(1984,1989)$, citado por Castro (2004, p. 46) são três as fases em que se subdivide a objetivação:

a) A construção seletiva: a partir do contato com os conhecimentos científicos, a sociedade se apropria desses conhecimentos, incorporando-os, de acordo com suas interpretações, para o seu universo conceitual comum. Uma ilustração da construção seletiva está disposta em:

(...) o professor, ainda como discente na universidade, estudou, com rigor, os diferentes campos da física, por meio de livros especializados e docentes pesquisadores das áreas. Pode-se afirmar que na universidade teve uma formação bastante próxima da ciência física. No entanto, ao chegar à escola como docente, 
entrará em contato com outros modelos e representações que também influenciarão no modo de ser professor (D1, 2007, p. 9).

Parece que diante das múltiplas interpretações de um mesmo fenômeno, os grupos sociais se apropriam dos conhecimentos, contextualizando-os de acordo com experiências cotidianas, respeitando as dimensões históricas e espaciais. No caso dos professores, o contexto é constituído pelos elementos que permeiam as instituições de ensino.

b) A esquematização estruturante (núcleo figurativo): nessa fase, existe um núcleo central que fundamenta a representação, determinando o seu significado e a sua organização, fornecendo a ideia básica transmitida pela representação;

c) A naturalização: é considerada a fase mais importante da representação em virtude de lhe atribuir uma função, fazendo-lhe produzir um efeito. Nela, as ideias criadas no senso comum tornam-se naturais.

E ancoragem, o que é? É classificar, dar nome a algo, é tornar conhecido algo desconhecido, ou, como nos aponta Serge Moscovici, é um processo que transforma algo estranho e perturbador, que nos intriga, em nosso sistema particular de categorias e o compara com um paradigma de uma categoria que nós pensamos ser apropriada. É como ancorar um bote perdido em um dos boxes (ponto sinalizador) de nosso espaço social (MOSCOVICI, 2003, p. 61).

Um exemplo disso é, quando diante do surgimento do problema da AIDS (Síndrome da Imunodeficiência Adquirida), as pessoas começaram a ter muitas dificuldades para entendê-la e classificá-la, sendo assim, uma das formas encontradas pelo senso comum para dar conta da sua ameaça foi ancorá-la como uma peste, dessa forma, a AIDS seria menos ameaçadora.

No processo de ancoragem, os acontecimentos são incorporados e reinterpretados coletivamente. De acordo com (JODELET, 1998), a ancoragem se organiza a partir de três condições estruturantes:

a) A atribuição do sentido: relaciona-se com a busca de incorporação do elemento novo, com base no molde antigo, para lhe atribuir significado. Na Dissertação D1 (2007, p. 18), temos um bom exemplo disso:

\footnotetext{
O astrônomo Johannes Kepler, inspirado na filosofia magnética de Willian Gilbert, sugeriu que os planetas, entre os quais a Terra, deviam ter algo semelhante a um eixo magnético (um gigantesco ímã) que os mantinha continuamente orientados do mesmo modo no espaço e que podiam produzir fases alternadas por serem atraídos ou repelidos pelo Sol, hipótese refutada pela Lei da Gravitação Universal de Isaac Newton (HENRY, 1998, p.26).
}

Dito de outro modo, a inspiração (molde antigo) na filosofia magnética parece ter indicado o caminho do raciocínio de Kepler quanto ao movimento dos planetas comparados a grandes imãs (elemento novo). Ainda que esta ideia tenha sido refutada, percebe-se atribuição de sentido a um fenômeno novo com base em conhecimentos anteriores.

b) A instrumentalização do saber: quando o sujeito interpreta o conhecimento novo, dando-lhe uma nova forma, traduzindo-o e incorporando-o ao seu universo social, possibilitando, dessa forma, a comunicação entre o grupo ou a sociedade;

Tal sujeito classifica o conceito em sua rede de significações, isto é, procede recorrendo ao que é familiar para fazer uma espécie de conversão da novidade: trazê-lo ao território conhecido da sua bagagem nocional, ancorar aí o novo, o desconhecido, retirando-o da sua navegação às cegas pelas águas do não familiar (ARRUDA, 2002, p. 136). 
c) O enraizamento no sistema de pensamento: representado pela estabilidade das representações, que se processa em função da inserção do novo no sistema de pensamento social prévio. Esse processo aparece na dissertação D1 da seguinte forma:

Como podemos perceber as representações sociais emergem de conflitos, de algo que nos perturba e essa sensação de desconforto nos impulsiona a buscar, em nossa rede de significações (a memória), palavras, gestos, silêncios - que traduzam nosso entendimento e/ou desejo de que este conceito/conhecimento seja trazido/traduzido ao nosso ambiente, ou melhor, a um universo que nos é familiar (D1, 2007, p. 19).

Nessa lógica de construção de uma representação, pensamos que as RS são fenômenos complexos, em que a mudança, a novidade e o dinamismo são três de suas principais características. Segundo Moscovici (citado por CASTRO, 2004, p. 44), formam-se três elementos que estruturam a representação social: a atitude, a informação e a imagem ou campo de representação:

a) Atitude - intenção que o indivíduo tem com relação ao objeto a ser representado e a expressa;

b) Informação - conjunto de conhecimentos sobre alguém ou algo; fato ou acontecimento levado ao conhecimento de alguém ou de um público por meio de palavras, sons ou imagens; elemento de conhecimento susceptível de ser transmitido e conservado graças a um suporte e um código;

Nessa lógica, a Dissertação D3 (2007, p. 20) observa que a pesquisa sobre concepções prévias e representações não só contribui para a compreensão do processo de aprendizagem de novas concepções, como respeita o aluno enquanto sujeito desse mesmo processo.

c) Imagem ou Campo de Representação - organiza-se em torno do esquema figurativo ou núcleo figurativo que atua como organizador para o conjunto da representação social. É quem atribui o peso e o significado dos elementos presentes na representação.

$\mathrm{Na}$ dissertação D4, temos um comentário elucidativo destes três elementos estruturantes:

(...) [eles] demonstram a "engrenagem complexa" das RS e trazem em seu bojo a expressão da vontade dos indivíduos/grupos em relação ao objeto representado, em que o conteúdo desta expressão corresponde a toda informação que os sujeitos acumulam, culturalmente, sobre o objeto susceptível de ser transmitido por meio de um código de comunicação (D4, 2010, p. 30).

Este processo culmina na formação da imagem do objeto representado, pois é o campo de representação quem seleciona os elementos importantes para o mesmo.

\section{NÚCLEO CENTRAL DAS REPRESENTAÇÕES SOCIAIS}

Outros conceitos também são incorporados à Teoria das RS. Como exemplo, citamos o Núcleo Central das representações que, diante de reflexões elucidativas das condições históricas, foi se constituindo como uma teoria - a teoria do Núcleo Central (NC).

A Teoria do Núcleo Central (NC) esclarece que as partes constituintes de uma representação estão organizadas hierarquicamente, em torno de um núcleo formado, que tem por função dar significado à representação. Isso posto, vemos o NC como a "alma" da representação, que carrega alguns atributos da representação. 
Esses atributos garantem o poder de representação da imagem, o qual, alguns autores denominam Poder Simbólico (MOLINER, citado por SÁ, 1996), funcionando como um modelo, de forma que na inexistência de um desses elementos centrais, o objeto não é mais reconhecido. Sendo assim, segundo Castro (2004, p. 48):

\begin{abstract}
A teoria permite descobrir a estrutura de uma representação, além de estabelecer a posição de cada um dos atributos da imagem, verificando assim quais os constituintes do núcleo central e quais fazem parte da periferia. Essa possibilidade existe em função do forte poder de associação dos elementos do núcleo central em relação aos outros atributos da imagem. Assim, em torno de cada um dos atributos centrais da informação, existe uma rede de informações periféricas (e também nucleares) que podem ser acessadas.
\end{abstract}

Na concepção de Abric (1994), o Núcleo Central de uma representação possui as seguintes características: diretamente associado às condições históricas, sociológicas e ideológicas; é parte compartilhada coletivamente, desempenhando uma função consensual; e é estável, coerente e resistente a mudanças, exercendo a função de permanência da representação.

Essas características apontam duas funções essenciais a serem cumpridas pelo NC: a função geradora, que cria ou transforma a significação dos demais elementos que constituem a representação, e a função organizadora, que determina a natureza das ligações que elementos estabelecem da representação entre si.

$\mathrm{O}$ excerto a seguir representa estas duas funções:

\begin{abstract}
Mediante análise das respostas emitidas pelos professores podemos afirmar que, de modo geral, eles se ancoraram nos conceitos de inércia, força e aceleração para explicar a permanência do movimento na pedra, isto é, estes conceitos apareceram como responsáveis pelo movimento. Entre os oito professores entrevistados, 5 (cinco) de algum modo, recorreram ao conceito de inércia, formulado por Isaac Newton, para explicar o "comportamento" da pedra. Suas representações se aproximaram muito da representação newtoniana (D1, 2007, p. 34).
\end{abstract}

Em boa parte das vezes, a maior frequência corresponde ao NC de uma representação, mas isso depende da ordem das evocações ${ }^{3}$ dos sujeitos investigados, o que nesse caso aproxima a representação da maioria dos sujeitos de uma ideia, noção (representação Newtoniana) pré-estabelecida e com certo nível de organização.

Já no que diz respeito aos elementos periféricos, podemos dizer que são determinados pelo contexto mais imediato, em que a flexibilidade e mobilidade são duas de suas características, possibilitando desempenhar as funções de: concretização; regulação e adaptação; e individualização da representação (ABRIC, 1998).

Nessa lógica, a teoria do NC sugere que o conteúdo das RS se apresenta organizado, constituindo não só um "tronco" central, em que estabilidade, rigidez e consenso são encontrados, como também uma "engrenagem" periférica, sendo nela encontradas um caráter mutável, flexível e individualizado.

3 Vergès (1992) desenvolveu uma técnica para caracterizar a estrutura de uma representação social a partir de evocações (manifestação da memória) de palavras. 


\section{CONSIDERAÇÕES FINAIS}

Este artigo organiza uma discussão de fundamentos epistemológicos característicos da Teoria das Representações Sociais em dissertações na área de Educação em Ciências. Com base nisso, verificamos conceitos oriundos das ciências sendo estudados a partir de grupos sociais específicos.

Observamos que, no conjunto das pesquisas, os estudos estão ancorados nos níveis fenomenológicos, porque elementos da realidade social, modos de conhecimento, saberes do senso comum que surgem e se legitimam na conversação interpessoal cotidiana e têm como objetivo compreender e controlar a realidade social; e metateóricos, pois foram feitos debates junto a comparações com outros modelos teóricos.

Com este texto, não buscamos fazer um estado da arte da Teoria das Representações Sociais, pois foram identificados e analisados alguns trabalhos em uma área, contudo nestes estão representados os níveis de aprofundamento da teoria das RS por pesquisadores da Educação em Ciências.

Verificamos a importância de um artigo como este, a qual é objetivada pela carência de estudos de natureza epistemológica que estabeleçam o diálogo entre as formas de construção de conhecimentos, que atribui um sentido prático a esta proposta.

As pesquisas baseadas na Teoria das Representações Sociais apontam para as várias abordagens como suficientes construções teóricas e metodológicas no que se refere às observações de fenômenos característicos da Educação em Ciências, especialmente quando se tratam de conceitos científicos, suas formas de apropriação pelo senso-comum e elucidação da dos processos de construção e partilha de conhecimentos.

Logo, poderá se naturalizar como mais um aporte para novos estudos nesta direção, haja vista que está materializada uma possibilidade de organização de elementos teóricos, dispersa pelo universo da Epistemologia da Pesquisa em Educação em Ciências.

\section{REFERÊNCIAS}

ABRIC, J.C. Pratiques sociales et représentations. Paris: Presses Universitaires de France, 1994.

A abordagem estrutural das representações sociais. Tradução de Pedro Humberto Faria Campos. In: Moreira, A. S. P. e Oliveira, D. C. (orgs.). Estudos interdisciplinares de representação social. Goiânia, AB, 1998.

ARRUDA, A. Teoria das Representações Sociais e Teoria de Gênero. Cad. Pesquisa, n. 117, São Paulo, 2002.

BARBOSA, R. G. A teoria das representações sociais para estudo das concepções docentes no ensino da física em nossas escolas: a física newtoniana. Maringá: [s.n], 2007 (Dissertação de Mestrado). Universidade Estadual de Maringá/PPG em Educação para a Ciência e o Ensino de Matemática.

CASTRO, S. M. V. Representação social de ciência de estudantes do ensino fundamental da rede municipal de Belém. Belém: [s.n], 2004 (Dissertação de Mestrado). UFPA / NPADC. 
GUARESCHI, P. A. "Sem dinheiro não há salvação": ancorando o bem e o mal entre os neopentecostais. In: GUARESCHI, P. A.; JOVCHELOVITCH, S. (Orgs.). Textos em representações sociais. 6. ed. Petrópolis: Vozes, 2000.

HENRY, John. A Revolução Cientifica: e as Origens da Ciência Moderna. Tradução: Maria Luiza X. de A. Borges - Rio de Janeiro: Jorge Zahar Ed. 1998.

JODELET, D. "La Representación Social: Fenómeno, Concepto e Teoria". In: MOSCOVICI, S. (Org). Psicologia Social. Buenos Aires: Paidós, 1986.

JODELET, D. A alteridade como produto e processo psicossocial. In: ARRUDA, A. (Org.). Representando a Alteridade. $2^{\text {a }}$ Ed. Petrópolis, 1998.

MARKOVÁ, I. Dialogicidade e Representações Sociais: as dinâmicas da mente. Trad. Hélio Magri Filho. Petrópolis, Rio de Janeiro: Vozes, 2006.

MARTINHO, L. R. e TALOMONI, J. L. B. Representações Sobre Meio Ambiente de Alunos da Quarta Série do Ensino Fundamental. Ciência \& Educação, v. 13, n. 1, p. 1-13, 2007

MORIN, E. O Método IV - As idéias: A natureza, Vida, Habitat e Organização. Lisboa, 1990.

MOSCOVICI, S. Representações Sociais: investigações em Psicologia Social. Petrópolis, RJ: Vozes, 2003.

OLIVEIRA, F.O. \& WERBA G.C. Representações sociais. In: STREY, M.N. (et al.) Psicologia Social Contemporânea: livro texto. 11ª ed. - Petrópolis, RJ: Vozes, 2008.

SÁ, C.P. Representações Sociais: o conceito e o estado atual da teoria. In: SPINK, Mary Jane (ORG). Conhecimento no Cotidiano: As representações sociais na perspectiva da Psicologia Social. São Paulo: Brasiliense, 1993.

- Núcleo Central das Representações Sociais. São Paulo, Vozes, 1996.

A construção do projeto de pesquisa em representações sociais. Rio de Janeiro: EdUERJ, 1998.

SANTOS, A. G. Representações Sociais do Ambiente por Professores e Estudantes em Diferentes Contextos Educacionais. /Orientadora: Maria de Fátima Vilhena da Silva NPADC/UFPA - Belém, 2010. (Dissertação de Mestrado).

SCHAFER, D. Z. Representações sociais de alunos universitários sobre o termo "ORGÂNICO": [s.n], 2007 (Dissertação de Mestrado). USP/ Institutos de

Física, Química, Biociências e à Faculdade de Educação da Universidade de São Paulo.

SILVA JUNIOR, A. G. Representação Social do conceito de Tempo nos Licenciandos da UFRPE: [s.n], 2006 (Dissertação de Mestrado). UFRPE/PPG em Ensino das Ciências.

SPINK, M. J. (ORG) Conhecimento no Cotidiano: As representações sociais na perspectiva da Psicologia Social. São Paulo: Brasiliense, 1993.

VERGÈS, P. L'évocation de l'argent: une méthode pour la définition du noyau central de la représentation. Bulletin de Psychologie, 45, p. 203-209, 1992.

XAVIER, Roseane. Representação social e ideologia: conceitos intercambiáveis? Recife: PPGS/UFPE. Texto mimeografado, 2002. 